\title{
Fabulário dos delírios tropicais: uma jornada caótica
}

Tales of tropical madness: a chaotic journey

\section{Almir Rosa}

Almir Rosa

Artista e escritor de prosa, verso e dramaturgia. Trabalha nas áreas de cultura, educação, assistência social e saúde mental, com projetos na cidade de Embu das Artes e nas periferias paulistanas.

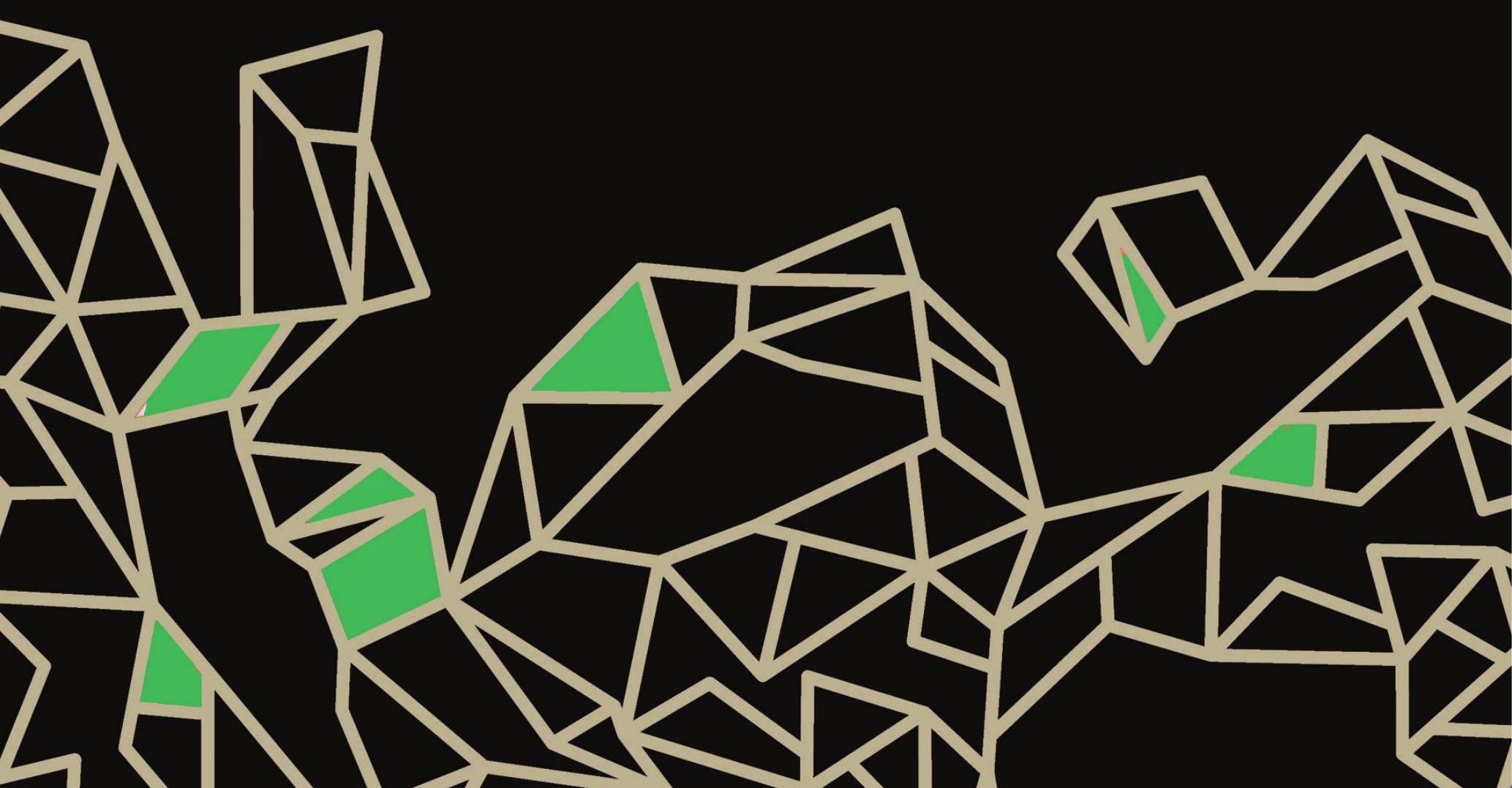


A redescoberta de uma nação através de sua identidade cultural, ressurgida na pluralidade, se faz necessária frente à decadência dos mecanismos de opressão. A forma genérica que sempre definiu o Brasil, abafando de modo violento a diversidade de uma nação, se mostra em plena derrocada perante a produção de singularidades daqueles que ainda buscam suas vozes.

Múltiplo, diverso, psicodélico e tropical. O Brasil vive seu momento mais caótico, sem deixar de acompanhar o caos global. Porém, nossos trópicos escaldantes tornam as efervescências ainda mais flamejantes. O lugar da fala, direção, recepção ou impacto que ela impele, são fatores pertinentes para nossa construção social. A democracia da expressão, confronto de opiniões, erros e corretivos acontecendo de forma imediata, um verdadeiro apocalipse tropical, pauta o suor de nossos dias e noites. Aos que sempre clamaram por alguma revolução, ela chegou. Espantosa como deveria ser, pois revolução, mesmo em sua etimologia, nos convida a interpretar seu significado. No mais, pode ser definida como algo que provoca uma transformação profunda. Porém, nos últimos tempos, podemos observar uma mudança radical em nosso desenho social. Os eixos que encaminhavam nossas diretrizes, guiados por uma visão mais homogênea da sociedade, foram cada vez mais bombardeados e hoje, após muita luta, passamos da passividade ao questionamento.

O Brasil tem grande destaque nesse momento de excitação global. 0 fato de ser um país relativamente novo, somado à diversidade marcante em sua identidade cultural, gerou demandas mais expansivas principalmente na gestão de políticas públicas, as quais seguiram os modelos de dinastias brancas que dominam boa parte do mundo. Entretanto, desprezar tamanha diversidade na construção político-social de um país de fato criou um vulcão. A estética de uma gestão branca e imperialista, no nosso caso, gerou diversos conflitos, a começar pelos de classe. O Brasil é dos países que conseguem a façanha de reunir extrema riqueza versus extrema pobreza, e essa conta inclui fortes conflitos em seu resultado.

A hegemonia delirante que simulou nossa identidade cultural de forma genérica por muito tempo foi enfraquecendo e, com a chegada de novas tecnologias, os levantes por melhores condições de existência ganharam mais corpo e principalmente vozes. 
Desde então, nossa máscara esculpida a base de pólvora e açoite começou a descolar da face nacional, revelando uma nação em múltiplas, diversas e plurais formas de existência.

Os novos canais de comunicação foram e ainda são porta-vozes de processos individuais, criando redes coletivas de trocas e afirmações das singularidades e complexidades correspondentes. Isso gerou um efeito semelhante a um espelho estilhaçado, antes uma única forma, mas que, após o impacto, fragmenta-se, criando vários recortes, vários espelhos. Vivemos um todo fragmentado, inclusive com subfragmentos dentro de cada fragmento. O potencial da possibilidade é explorado de forma radical. Mundos e mais mundos emergem de nosso caldo tropical criando o maior curto-circuito de nossa história.

Chimamanda Ngozi Adichie, autora nigeriana, nos alerta para os perigos de uma história só, descrevendo a partir de seus próprios caminhos como construiu seu imaginário através de símbolos que não faziam parte de sua natureza étnica e cultural. Até perceber que a maioria daqueles símbolos, arquétipos e cultura não a representavam de fato. No entanto, boa parte de sua vida foi escrita dessa forma. Nesse caso, podemos inverter a lógica da expressão "deixar as coisas claras" e traduzir ao pé da letra por "deixar as coisas escuras".

Essa observação dentro do recorte racial é uma navalha na liga, como diria Itamar Assumpção. A partir da escravidão e de sua manutenção, privam negras e negros de suas próprias histórias, entalhando na subjetividade preta um imaginário branco.

A luta dos movimentos pela valorização e continuidade de suas origens e pela afirmação de suas histórias e culturas passou a confrontar a supremacia branca do alto de sua jurisdição.

Os avanços nesses territórios são fundamentais para sua progressão, haja vista a prontidão dos movimentos para defendê-lo. A necessidade dessa transformação perpassa interesses isolados e se torna notória para nosso desenvolvimento mais coletivo. As divergências que sempre foram controladas através da opressão bruta passam a ser questionadas no ato de sua expressão espontânea. A vida do branco perdeu um tanto de seu conforto, ainda que sutil, perante a imensa paisagem nefasta que construíram ao longo dos séculos. Mas alguma sinapse acende dentro de algumas cabeças ocas. 
O racismo é um câncer social que atua em diversas esferas. Os efeitos colaterais desse mal secular atuam nas áreas mais subjetivas da população negra. Daí, é natural que os negros tenham maior entendimento sobre suas próprias questões e sejam seus melhores representantes. A parada é que o branco geralmente força a barra e não aceita sua condição de estar fora dessa conversa. Impondo sua posição imperialista, defendendo seu direito de opinar sobre todo e qualquer assunto. Traço forte da dinastia machista também. Nesse caso, um homem branco tem potencial duplo para cair no pântano de si mesmo. Enquanto o negro aponta a direção de seus caminhos e escurece as questões, o branco naufraga na incapacidade de se posicionar nesse diagrama. Vira refém de seu próprio mal, sem conseguir enxergar qual seria seu trabalho e contribuição frente ao racismo.

\section{Plantão papo reto!}

A parada é a seguinte: os brancos dominaram a porra toda, desde sempre. Aí, depois de muito chicote, muita rajada e muita treta, a coisa começa a virar. Aí tem que ficar dando orelhada pra branco que não se encontra na pegada? Tem até uma cota de paciência viu, mas é pouca. Faz sua correria parça! Ceis tão cercado de privilégios, usa essa parada pra alguma coisa que não seja a manutenção de vocês mesmos!! Aproveita o acesso e se adianta!

A segregação dos negros no Brasil e a manutenção escravocrata, que ainda se encontram vigentes, mantêm a tensão acerca de muitas questões. Enquanto a população negra fizer parte da estética da pobreza, essa conta não vai fechar, principalmente por ser o maior contingente populacional brasileiro. No entanto, a afirmação da negritude encontra-se em plena atividade, em vários ambientes, sempre de prontidão a tratar qualquer questão que a envolva, principalmente quando lhe falta alguma representatividade. Infelizmente, ainda é comum os assuntos de origem negra serem tratados por brancos. Basta ver os diversos casos de apropriação cultural, em que as comunidades negras precisam vir à tona e defender suas histórias e culturas em detrimento de pessoas que definem por elas mesmas que não há nenhum mal em se apoderar de estéticas culturais de outros povos. Esse pensamento carrega a lógica do opressor, que passa batido por qualquer reflexão que 
o impeça de realizar algo a favor de seu prazer, normatizando tudo ao seu redor, cadenciando para que as coisas partam do seu centro, mesmo os assuntos que não o incluem. $\mathrm{O}$ branco tem dificuldade de se rever, de não poder participar de tudo, mesmo que seja pra criticar a si próprio, quer fazer uso de seu direito de falar, não conseguindo desenvolver um raciocínio que o coloque inferior àquilo que sempre oprimiu.

Não é difícil de entender, pelo menos, um pouco das muitas questões que envolvem o recorte racial. São contas exatas, contas antigas, que hoje podemos olhar para alguns sintomas de reparação, avanços em políticas públicas, novos modelos de construção de futuro, a partir dos princípios de igualdade racial. Pra não chover no molhado, temos que olhar para as demandas mais intangíveis, os efeitos colaterais mais verticais. $E$ isso vai lançar olhos para a diversidade nos próprios movimentos. As causas que os negros defendem, de ordem coletiva, logicamente partem das demandas pessoais, mas quando aproximamos a lupa e enxergamos o indivíduo, vamos nos deparar com a mesma diversidade, vista em alto-relevo no nosso desenho social atual.

As diferenças ganham maior presença, amplificadas pelas redes sociais. $\mathrm{O}$ indivíduo ganha ares de representatividade tal qual fosse um partido ou agrupamento, fala e defende seus ideais, ainda que não estejam amadurecidos, mas estão prontamente defendidos. Isso tudo tem um ar de novidade, talvez ainda vamos ficar nessa neblina por um bom tempo, ainda vivemos a sombra do opressor, e, por outro lado, a expansão e democratização de alguns meios de comunicação tornaram possível uma participação mais efetiva da maioria das pessoas. Obviamente que isso vai gerar muita confusão, pois se trata de um processo de afloramento, muito intuitivo, e, diga-se de passagem, a intuição também não teve muito espaço dentro de nossas construções, vivemos, como diria o disco dos Titãs, tudo ao mesmo tempo agora, sem espaços temporais para medir nossos movimentos, declarando a importância de todas as vozes.

A convergência dessas vozes ganha altas frequências de complexidades, devido à relevância que cada uma delas impõe. Isso, de fato, tem contornos naturais, pois muitas dessas elocuções estavam devidamente amordaçadas há séculos, principalmente se tratando de comunidades segregadas. Os traçados que conduziam nossas questões, delineados por um padrão 
excludente, enfraquecem, perdem função e passam a ser substituídos por algo que ainda não tem forma definida, mas aponta outros e melhores rumos. Isso reforça o sentido de construção e nos provoca a cadenciar o tempo e encontrar lugares de fala e escuta, nessa costura tão necessária para um desenvolvimento progressista.

A verdade é que vivemos uma confusão lascada. Os grupos que sempre estiveram à margem ganham mais espaços, devido às suas próprias conquistas, enquanto outros se perdem num novo modelo de vida coletiva. Nesse caso, o branco sai em enorme desvantagem nessa construção pelo fato de sempre ter ocupado os lugares de controle e gestão, não sabendo se alocar num formato mais horizontal, onde abre mão de seus privilégios e precisa reconfigurar seus sistemas para uma compreensão maior para os fins coletivos, e, nesse caso, fica órfão de si próprio, pois seus conflitos não são prioridades nas pautas modernas. Isto deve deixar os brancos absolutamente desnorteados, pois nunca tiveram que se preocupar em rever seus lugares, sempre foram áreas tão privilegiadas a ponto de não precisar pensar sobre elas. Ainda que seja um processo complexo, a princípio o branco só pode contar com ele mesmo para atravessar esse deserto. Muitas comunidades estão à frente nas prioridades, principalmente pelo mal provocado pelo próprio branco. Difícil ter ajuda nessa hora, mesmo através de um olhar distanciado para os conflitos que os brancos geraram a eles próprios. Primeiro temos que atender as vítimas que eles atingem diariamente, inclusive de forma mortal. Esse recorte tem aspectos parecidos com problemáticas relacionadas ao machismo: ainda que o homem, de alguma forma, seja refém do padrão que criou, as vítimas que isso gerou são piores, um verdadeiro horror destilado de forma impune ainda nos dias de hoje. Nesse caso também é um caminho de pedras, infinitamente inferior aos danos que causam até hoje. A necessidade de mudança para o homem e para o branco não aparenta legitimidade inicial. Essa mudança tem a ver com destruir a si mesmo, ir contra sua própria construção. Sem ter a quem apontar enquanto um inimigo declarado, o branco luta consigo mesmo e, apesar dessa conta não aparentar uma mola propulsora, arrisco a dizer que existam frações da mais pura preguiça para fazer essa conta toda, diferente das minorias e comunidades segregadas que sabem bem apontar quem as oprime e os caminhos que buscam. Um grande 
problema é que esse processo do branco pode levar séculos infindáveis, pois depende de sua autocrítica, autoconhecimento e muita disposição pra pegar essa contramão imprescindível ao nosso desenvolvimento coletivo, porém ausente de lógica para quem se sente confortável na gestão opressora.

A confusão é grande, mas as perspectivas podem ser muito boas, daí a importância de também pensarmos no futuro. A urgência dos dias muitas vezes nos aprisiona num presente sufocante, e é essencial pensar os rumos que nossas construções terão. Muitas vezes, estamos matando um leão por dia para sobreviver a uma tempestade de demandas, e nos faltam tempo e oportunidades para projetar um futuro mais de acordo com nossos melhores propósitos. No momento, além das lutas, vivemos uma espécie de frenesi por nossas demandas terem encontrado amplificações. Acredito que isso faça parte de um processo, e logo poderemos observar as coisas de uma forma um pouco mais distanciada e com traços de uma nova lucidez.

Sobre o espetáculo Branco. Queria ter visto o branco ser agredido por ele mesmo, em pontos cirúrgicos, onde mais poderiam abalar suas próprias estruturas. Queria ter visto o branco feito um verdadeiro porco-espinho, repleto de agulhas de acupuntura distribuídas por todo seu corpo, num rito de exposição e cura, queria ter visto a plateia saindo envergonhada, buscando refúgio dentro de seus casacos, debaixo de seus próprios sovacos, e não da forma habitual que saem dos teatros, com as mesmas risadinhas e um ar privilegiado de quem assistiu uma peça foda. Se tratando do concreto em que o branco se construiu, ele pode ser sabotador das expressões que o denunciam, daí o estudo de caso, pra afinar a mira, quando o alvo do branco for ele mesmo.

Gostei da peça, não gostei da plateia. Gostações a parte, pode tascar umas quatro horas de peça no lombo da plateia branca, sem intervalo, sem café e sem massagem, cadeira dura, dar trabalho pra essa turma. Eles não vão soltar o osso.

A chapa esquentou, a tampa foi levantada e surgimos em plena ebulição. Mil tretas, mil fitas, corações agonizantes, divididos entre pequenas alegrias e o alto teor de sal que escorre do suor e das lágrimas. Tem muita gente fodida, muita! $\mathrm{E}$ ainda que isso ressalte algum sofrimento do branco, ele paga por suas próprias ações. Não tem outro jeito, a não ser ir pro fim da fila, malandro! 
E recorrer a seus processos o mais rápido possível a fim de reduzir os danos causados diariamente.

As pautas aumentaram de acordo com nosso design de diversidade. Temos que ouvir negras e negros, mulheres, gays, lésbicas, travestis e todas as vozes que foram silenciadas ao longo de todo esse tempo. Essas vozes questionam seus direitos e conversam entre si, sobre suas diferenças e progressões. Ao passo que vivemos uma revolução da fala, ao branco resta se revolucionar através da escuta e buscar caminhos para retornar a si mesmo na tentativa de encontrar alguém modificado. Hoje em dia, graças aos movimentos organizados, as coisas vão deixando de ser tratadas de forma genérica e ausente de contextos reais, e passam a compor uma costura feita por várias mãos, corações e espíritos. Com todas as vozes e expressões relevantes em nosso contexto atual, centenas ainda são assassinadas numa configuração clara de um genocídio.

A galera chegou e chegou forte, manas, manos e monas muito bem representados por suas vozes individuais e força coletiva, fazendo política com as próprias mãos, se reinventando e transformando seus entornos antes que nos enterrassem de vez. O branco só dá sinais de continuar o mesmo, sempre querendo preservar seus domínios, mas tem uma onda que cresce e avança feito um tsunami, trazendo a dignidade, singularidade e subjetividade daqueles que sempre foram e ainda são oprimidos. Apesar dos contornos fascistas que nos atormentam todos os dias, tá bonito de ver o quanto a produção negra cresceu e toma conta dos espaços, o quanto nossa diversidade produziu nos últimos tempos, nas artes, nas produções independentes. A periferia de São Paulo está fortíssima em vários setores, principalmente o cultural. Se a gente já era quente, agora o bagulho tá fervendo, daí os caras ficam em choque e querem censurar a parada toda, frear de qualquer jeito, mas agora não adianta, não tem mais volta, ou o branco se coça ou vai padecer de seu veneno. 